Supporting Information

\title{
Surface Thiolation of Al Microspheres to Deposite Thin and Compact Ag Shells for High Conductivity
}

Yilong Wang, ${ }^{a, b}$ Jianghong Wen, ${ }^{b}$ Suling Zhao, ${ }^{a, c}$ Zhihong Chen, ${ }^{a, d}$ Ke Ren, ${ }^{a}$ Jie

Sun $^{a}$ and Jianguo Guan*, a

${ }^{a}$ State Key Laboratory of Advanced Technology for Materials Synthesis and

Processing, Wuhan University of Technology, Wuhan 430070, P. R. China. Fax:

86-27-87879468; Tel: 86-27-87218832; E-mail: guanjg@whut.edu.cn.

${ }^{b}$ School of Chemistry, Chemical Engineering and Life Science, Wuhan University of

Technology, Wuhan 430070, P. R. China.

${ }^{c}$ Center for Material Research and Analysis, Wuhan University of Technology,

Wuhan 430070, P. R. China.

${ }^{d}$ School of Science, Wuhan University of Technology, Wuhan 430070, P. R. China. 


\section{Supporting Tables:}

Table S1. The influence of Al-MPTMS synthesized at various $F$ values on the silver crystallite size of the $\mathrm{Al} @ \mathrm{Ag}$ composite particles synthesized at $V_{\mathrm{A}}=20.00 \mathrm{~mL}$.

\begin{tabular}{cc}
\hline$F$ & Grain sizes $(\mathrm{nm})$ \\
\hline $1: 1$ & 21.7 \\
$1: 3$ & 20.2 \\
$0: 1$ & 21.5 \\
\hline
\end{tabular}




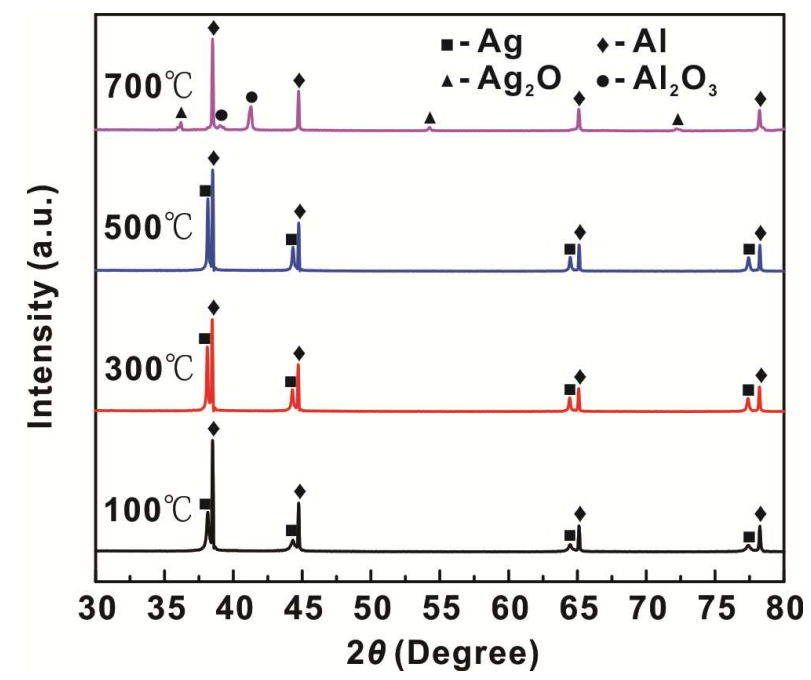

Figure S1. The influence of thermal treatment temperature on XRD patterns of the Al@Ag core-shell composite particles synthesized at $V_{\mathrm{A}}=20.00 \mathrm{~mL}$. 


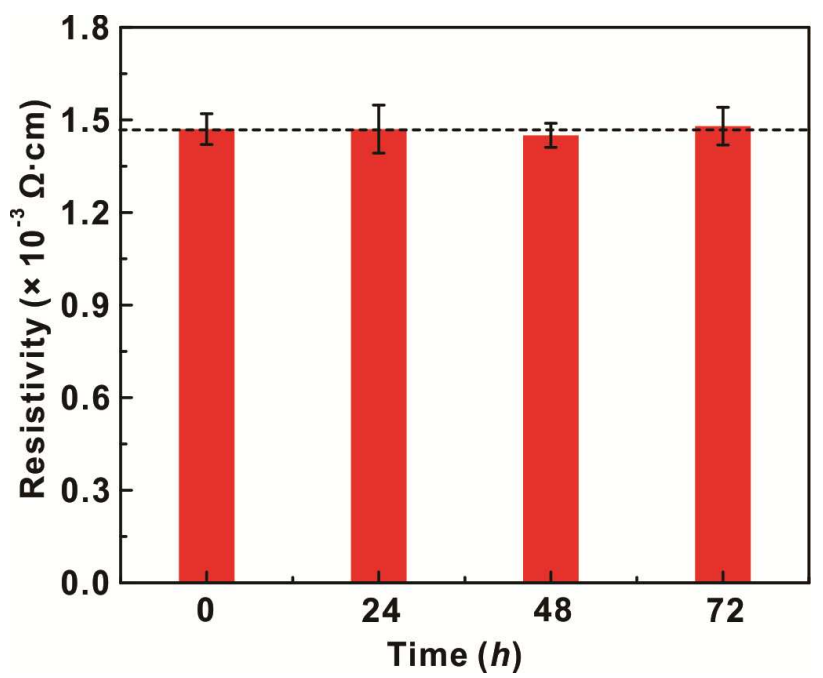

Figure S2. The effect of aging time on the resistivities of the ECA containing 45 vol\%Al@Ag core-shell composite particles synthesized at $V_{\mathrm{A}}=20.00 \mathrm{~mL}$. 